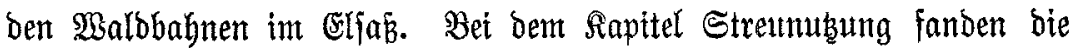
wertoollen Itnterjuchungsergebniffe Dr. Blettels über den verberblicten

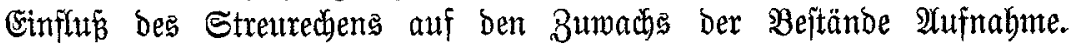
Die Berlaggbuchlyandlung hat eine bem gebiegenen Snhalt entiprechende

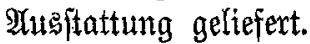

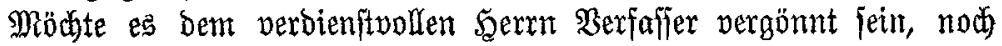
weitere $\mathfrak{A}$ uflagen jeines $\mathfrak{B e r k e s}$ jalbit zu beforgen.

\title{
IV. Mlatitizen.
}

Wirtihaftsergebnifie der Staats= und Domänenforften in Thüringen und Sachfen.

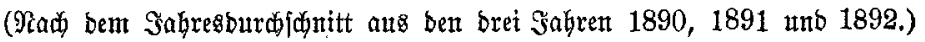

(Selegentlic ber 24. Berfammlung Thïringer Forftwixte in Sonneberg madte

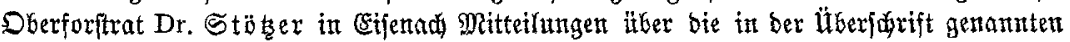
wirtjuaftliden Ergebniffe. Der Beridterftatter itfer biefe $\mathfrak{B}$ erjammllung teilt bie inter= effanten 3ablent in ber nadjplgenben Tabelfe mit bent Bemerfent ntit, baf̃ er benfelben now die ßrozentffalent beigefügt Gabe.

(Silke $\mathfrak{z a b e f l e}$ S. 344.)

\section{Ein verftetnerter Utrwald.}

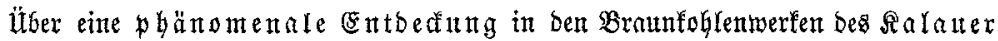
Rretjes geben bem "Berl. Tgbl." von etnem beteifigten Serrn folgende Mittteilungent

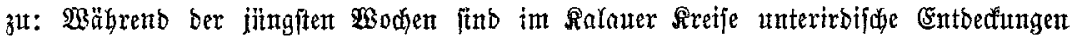

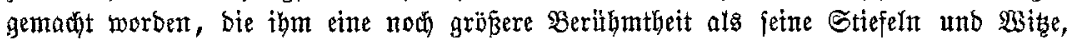
uns ztoar fïr alle Beiten berfalffen werben. Sn ben Braunfoblengrtben Biftoria uno Marie II waren feit langer Zeit bie 2 trbeiter mit einer getwiffen Megelmäßigleit am

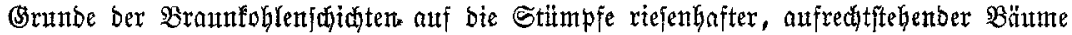

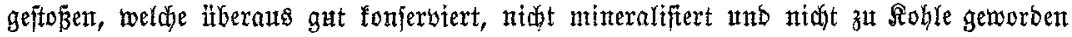

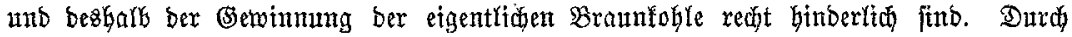
einent Buffall erfuthr bie Direftion ber geologifajen \&ndesanftalt Giervon und entiendete

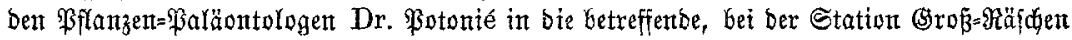

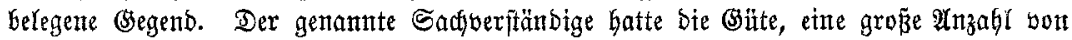

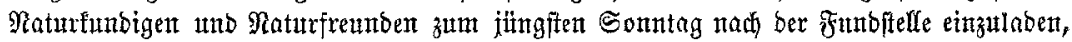

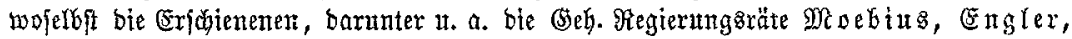

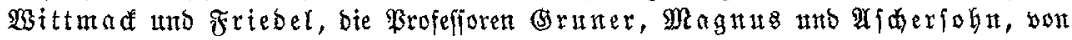

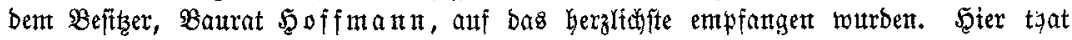

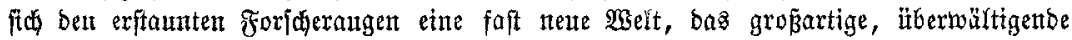

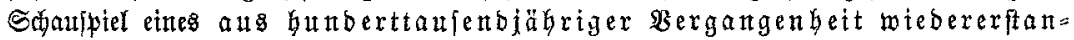

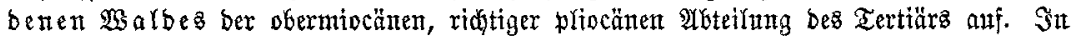
Geiben Tagebanten, auf einer mehrere Morgen groß̉en, Gorizontal liegenden glähe ex= 